\title{
Endogenous n-3 Fatty Acids Alleviate Carbon-Tetrachloride-Induced Acute Liver Injury in Fat-1 Transgenic Mice
}

\author{
Ruibing Feng, ${ }^{1}$ Meng Wang, ${ }^{1}$ Chunyan Yan, ${ }^{2}$ Peng Li, ${ }^{1}$ Meiwan Chen, ${ }^{1}$ \\ Chengwei He, ${ }^{1}$ and Jian-Bo Wan ${ }^{1}$ \\ ${ }^{1}$ State Key Laboratory of Quality Research in Chinese Medicine, Institute of Chinese Medical Sciences, University of Macau, Macau \\ ${ }^{2}$ College of Pharmacy, Guangdong Pharmaceutical University, Guangzhou 510006, China
}

Correspondence should be addressed to Chengwei He; chengweihe@umac.mo and Jian-Bo Wan; jbwan@umac.mo

Received 6 September 2016; Accepted 11 October 2016

Academic Editor: Ravirajsinh Jadeja

Copyright (c) 2016 Ruibing Feng et al. This is an open access article distributed under the Creative Commons Attribution License, which permits unrestricted use, distribution, and reproduction in any medium, provided the original work is properly cited.

n-3 polyunsaturated fatty acids (PUFAs) are beneficial for numerous models of liver diseases. The probable protective effects of $n-3$ PUFA against carbon-tetrachloride- $\left(\mathrm{CCl}_{4}^{-}\right)$induced acute liver injury were evaluated in a fat-1 transgenic mouse that synthesizes endogenous n-3 from n-6 PUFA. Fat-1 mice and their WT littermates were fed a modified AIN93 diet containing $10 \%$ corn oil and were injected intraperitoneally with a single dose of $\mathrm{CCl}_{4}$ or vehicle. $\mathrm{CCl}_{4}$ challenge caused severe liver injury in WT mice, as indicated by serum parameters and histopathological changes, which were remarkably ameliorated in fat-1 mice. Endogenous n-3 PUFA decreased the elevation of oxidative stress induced by $\mathrm{CCl}_{4}$ challenge, which might be attributed to the activation of Nrf2/keapl pathway. Additionally, endogenous n-3 PUFA reduces hepatocyte apoptosis via suppressing MAPK pathway. These findings indicate that n-3 PUFA has potent protective effects against acute liver injury induced by $\mathrm{CCl}_{4}$ in mice, suggesting that $\mathrm{n}-3$ PUFA can be used for the prevention and treatment of liver injury.

\section{Introduction}

Liver is a vital organ that has extensive synthetic, metabolic, and detoxifying functions [1]. This tissue is also a main target that is subject to acute or chronic injury induced by a variety of drugs or xenobiotics, such as alcohol, heavy metals, and carbon tetrachloride $\left(\mathrm{CCl}_{4}\right)$ [2]. $\mathrm{CCl}_{4}$, an analogue of human hepatotoxin, has been widely used in in vitro and in vivo models to induce liver injury [3]. $\mathrm{CCl}_{4}$ is oxidized by cytochrome P4502E1 (CYP2E1) in the liver to generate the highly reactive species, such as trichloromethyl $\left({ }^{\circ} \mathrm{CCl}_{3}\right)$ and peroxy trichloromethyl $\left({ }^{\circ} \mathrm{OOCCl}_{3}\right)$ radicals [4], which can trigger oxidative stress, lipid peroxidation, and hepatocyte apoptosis, leading ultimately to hepatotoxicity [5].

Oxidative stress is mainly responsible for the pathogenesis of $\mathrm{CCl}_{4}$-induced liver injury, which can disturb the redox homeostasis and elevate the excessive production of reactive oxygen species (ROS) [6]. Antioxidant defense system, including nonenzymatic antioxidants and enzymatic antioxidants, contributes to protecting the liver against oxidative stress in living organisms. The expressions of these antioxidative enzymes are regulated by a redox-sensitive transcription factor, nuclear factor-erythroid 2-related factor-2 (Nrf2), and its downstream proteins, including heme oxygenase-1 (HO1), glutamate cysteine ligase (GCL), and NAD(P)H:quinone oxidoreductase-1 (NQO1) [7, 8]. Oxidative stress also elevates cytochrome $\mathrm{C}$ in the cytoplasm which is released from the mitochondria, which induces the activation of caspase cascades, eventually leading to hepatocyte apoptosis.

Growing evidence indicates that $n-3$ polyunsaturated fatty acids (PUFAs), mainly $\alpha$-linolenic acid (ALA), eicosapentaenoic acid (EPA), and docosahexaenoic acid (DHA), exhibit profoundly therapeutic efficacy in several models of liver disease, including nonalcoholic liver disease [9], parenteral nutrition-associated liver disease [10], alcoholinduced liver injury [11], hepatic steatosis [12, 13], and 
D-galactosamine/lipopolysaccharide-induced hepatitis [14]. However, the impacts of n-3 PUFA on $\mathrm{CCl}_{4}$-induced liver injury have not been sufficiently addressed. The fat-1 transgenic mouse was genetically modified to express a fat-1 gene that encodes n-3 PUFA desaturase $[15,16]$. This enzyme can endogenously convert n-6 PUFA to n-3 PUFA in mammals, leading to higher n-3 PUFA level in tissues from fat-1 mice, compared to the wild-type (WT) littermates when fed the same diet rich in n-6 PUFA. Thus, fat-1 mice are a wellestablished animal model to investigate the role of n-3 PUFA in $\mathrm{CCl}_{4}$-induced liver injury. Therefore, the aims of current study are to evaluate the probable effects of n-3 PUFA against $\mathrm{CCl}_{4}$-induced acute liver injury and to elucidate the potential molecular mechanisms underlying this action.

\section{Materials and Methods}

2.1. Animals and Treatments. Fat-1 transgenic mice with a genetic background of C57BL/6 were provided by Dr. Jing $\mathrm{X}$. Kang's lab at Massachusetts General Hospital (Boston, MA, USA). Male heterozygous fat-1 mice were crossed with C57BL/6 female mice to yield heterozygous fat-1 and WT offspring. The fat-1 phenotype of each offspring was identified by the analysis of total lipids from mouse tail by using gas chromatography-mass spectrometry (GC-MS). The female fat-1-positive and WT littermates were maintained in a specific pathogen-free room at the Experimental Animal Center, Guangdong Pharmaceutical University. Mice were fed an n6 PUFA-rich but n-3 PUFA-deficient diet (a modified AIN93 containing $10 \%$ corn oil), which contains $20 \%$ protein, $58 \%$ carbohydrate, and 22\% fat (TROPHIC Animal Feed HighTech Co., Ltd., Nantong, China). Mice (10-12 weeks old) were divided into three groups $(n=10)$, that is, WT control, $\mathrm{WT} / \mathrm{CCl}_{4}$, and $\mathrm{fat}-1 / \mathrm{CCl}_{4}$ groups. The mice in $\mathrm{CCl}_{4}$ challenge groups were injected intraperitoneally with $10 \mathrm{~mL} / \mathrm{kg} \mathrm{CCl}_{4}$ $(0.2 \%$, dissolved in olive oil) [17], while WT controls received an equal volume olive oil (i.p.). After $24 \mathrm{~h}$ of $\mathrm{CCl}_{4}$ or vehicle treatment, all mice were anesthetized by an injection (i.p., $100 \mathrm{mg} / \mathrm{kg}$ ) with sodium pentobarbital. Blood samples and liver tissues were immediately collected. The animal experimental protocols (ICMS-AEC-2015-028) were performed according to the Guide to Animal Use and Care of the University of Macau and were approved by the ethics committee.

2.2. Analysis of Fatty Acid Composition in the Liver. Fatty acid profile was analyzed according to a simplified method by using GC-MS, as described previously $[18,19]$. In brief, approximately $10 \mathrm{mg}$ of liver tissue was ground in liquid nitrogen and methylated with $1.5 \mathrm{~mL}$ of $14 \%$ boron trifluoridemethanol reagent (Sigma-Aldrich) and $1.5 \mathrm{~mL}$ of hexane at $100^{\circ} \mathrm{C}$ for $1 \mathrm{~h}$. After cooling, fatty acid methyl esters (FAME) were extracted in upper hexane layer. GC-MS analysis was conducted on a Thermo Fisher Scientific ISQ Series Single Quadrupole GC-MS system equipped with a TriPlus $\mathrm{RSH}^{\mathrm{TM}}$ autosampler (Thermo Fisher, Waltham, MA, USA). Separation of FAME was achieved on an Omegawax ${ }^{\mathrm{TM}} 250$ fused silica capillary column $(30 \mathrm{~m} \times 0.25 \mathrm{~mm}$ i.d., $0.25 \mu \mathrm{m}$ film thickness, Supelco, Bellefonte, PA). The optimum oven temperature program was as follows: it was initially set at $180^{\circ} \mathrm{C}$ for $3 \mathrm{~min}$, ramped to $206^{\circ} \mathrm{C}$ at $2^{\circ} \mathrm{C} / \mathrm{min}$, held at $206^{\circ} \mathrm{C}$ for $25 \mathrm{~min}$, ramped to $240^{\circ} \mathrm{C}$ at $10^{\circ} \mathrm{C} / \mathrm{min}$, and held at $240^{\circ} \mathrm{C}$ for $5 \mathrm{~min}$. Peaks in the chromatogram were identified by comparing their retention times and mass spectrums with GLC-461 reference standard (Nu-Chek Prep, Elysian, MN, USA) containing 32 FAME.

2.3. Measurement of Serum Aminotransferase Levels. Activities of serum aspartate aminotransferase (AST) and alanine aminotransferase (ALT) were colorimetrically examined by using their commercial kits (Nanjing Jiancheng Bioengineering Institute, Nanjing, China).

\subsection{Determination of Oxidative Stress Parameters in the Liver.} Partial liver tissues were weighed and homogenized with cold radioimmunoprecipitation assay (RIPA) buffer (Beyotime Institute of Biotechnology, Nanjing, China) to prepare $10 \%$ liver homogenate. After centrifugation, the supernatant was subjected to measure the levels of malondialdehyde (MDA), reduced glutathione (GSH), and oxidized glutathione (GSSG) and the activities of catalase (CAT), glutathione peroxidase (GSH-Px), glutathione reductase (GR), and superoxide dismutase (SOD) in the liver, by the corresponding kits (Nanjing Jiancheng Bioengineering Institute). Total proteins in the homogenate were quantified using Pierce ${ }^{\mathrm{TM}}$ BCA Kit (Thermo Fisher). Values were normalized against hepatic total protein content.

2.5. Histopathological Analysis. Histopathological changes of the liver were observed by hematoxylin and eosin (H\&E) staining [20]. The liver tissue from the same lobe in each mouse was fixed in $10 \%$ formalin overnight, dehydrated in alcohol with different concentrations, and embedded in paraffin. The liver sections ( $5 \mu \mathrm{m}$ thickness) were stained with $\mathrm{H} \& \mathrm{E}$ using a standard protocol. The histopathological changes of each mouse were examined and photographed by an Olympus CX-31 light microscope (Olympus Corp., Tokyo, Japan).

2.6. TUNEL Assay. To evaluate apoptotic cells in the liver tissue, a terminal deoxynucleotidyl transferase-mediated deoxyuridine 5-triphosphate (dUTP) nick end labeling (TUNEL) assay was conducted by using ApopTag ${ }^{\circledR}$ Plus In Situ Apoptosis Fluorescein Detection Kit (S7111, EMD Millipore Corporation, Billerica, MA, USA). In brief, liver cryostat section $(8 \mu \mathrm{M})$ was fixed in $1 \%$ paraformaldehyde and washed with PBS three times. Then, the section was incubated with green fluorescein labeled dUTP solution at $37^{\circ} \mathrm{C}$ for $1 \mathrm{~h}$. The section was counterstained with DAPI and examined using an Olympus BX63 fluorescence microscope (Tokyo, Japan).

2.7. Immunofluorescence Assay. Immunofluorescence analysis of hepatic Nrf2 was conducted as described previously [15]. Briefly, the cryostat section of liver tissue $(8 \mu \mathrm{M})$ was fixed in cooled acetone for $10 \mathrm{~min}$ at $4^{\circ} \mathrm{C}$ and then washed with PBS. After blocking the endogenous peroxidase with $5 \%$ goat serum for $20 \mathrm{~min}$, the liver section was incubated with 
TABLE 1: The primer sequences used in quantitative reverse transcription PCR analysis.

\begin{tabular}{|c|c|c|c|}
\hline Gene & Full name & GenBank accession number & Primer sequences (forward/reverse) \\
\hline \multirow{2}{*}{$\mathrm{HO}-1$} & \multirow{2}{*}{ Heme oxygenase-1 } & \multirow{2}{*}{ NM_010442 } & 5'-AAGCCGAGAATGCTGAGTTCA-3' \\
\hline & & & $5^{\prime}$-GCCGTGTAGATATGGTACAAGGA-3' \\
\hline \multirow{2}{*}{ GCLC } & \multirow{2}{*}{$\begin{array}{l}\text { Glutamate cysteine ligase } \\
\text { catalytic subunit }\end{array}$} & \multirow{2}{*}{ NM_010295 } & 5'-GGGGTGACGAGGTGGAGTA-3' \\
\hline & & & 5'-GTTGGGGTTTGTCCTCTCCC-3' \\
\hline \multirow{2}{*}{ GCLM } & \multirow{2}{*}{$\begin{array}{l}\text { Glutamate cysteine ligase } \\
\text { modifier subunit }\end{array}$} & \multirow{2}{*}{ NM_008129 } & $5^{\prime}$-AGGAGCTTCGGGACTGTATCC-3' \\
\hline & & & $5^{\prime}$-GGGACATGGTGCATTCCAAAA-3' \\
\hline \multirow{2}{*}{ NQO1 } & \multirow{2}{*}{ Quinone oxidoreductase-1 } & \multirow{2}{*}{ NM_008706 } & $5^{\prime}$-AGGATGGGAGGTACTCGAATC-3' \\
\hline & & & 5'-AGGCGTCCTTCCTTATATGCTA-3' \\
\hline \multirow{2}{*}{ GADPH } & \multirow{2}{*}{$\begin{array}{l}\text { Glyceraldehyde-3-phosphate } \\
\text { dehydrogenase }\end{array}$} & \multirow{2}{*}{ NM_008085 } & $5^{\prime}$-TGGATTTGGACGCATTGGTC-3' \\
\hline & & & $5^{\prime}$-TTTGCACTGGTACGTGTTGAT-3' \\
\hline
\end{tabular}

1:100 rabbit anti-mouse Nrf2 antibody (Santa Cruz Biotechnology, Dallas, USA) at $4^{\circ} \mathrm{C}$ overnight and then incubated with 1:1000 Alexa Fluor ${ }^{\circledR}$ 568-labeled secondary antibody (Life Technologies, Carlsbad, CA, USA) in the dark at room temperature for $1 \mathrm{~h}$. Nuclei were counterstained with DAPI for $10 \mathrm{~min}$. The fluorescence was observed and photographed by an Olympus BX63 fluorescent microscope (Olympus).

2.8. RT-PCR Assay. Total RNA from the same lobe of liver tissue was extracted by a commercial RNAiso Plus kit according to the manufacturer's protocol (Takara, Tokyo, Japan). cDNA was synthesized by reverse transcription and amplified by PCR with the primers shown in Table 1 using PrimeScript RT Reagent kit (Takara). The sequence of primers was designed from the PrimerBank and synthesized by Invitrogen Life Technologies (Shanghai, China). PCR products were separated by agarose gel electrophoresis, stained with ethidium bromide, and visualized under UV light.

2.9. Western Blotting Assay. Total protein, cytosolic protein (exclusively for Nrf2), and nuclear protein (exclusively for Nrf2) from liver tissues were prepared. Total proteins were isolated from liver tissue by RIPA buffer with $1 \%$ phosphatase and protease inhibitors (Beyotime). The extraction and isolation of nuclear and cytosolic proteins were conducted by a Nuclear and Cytoplasmic Protein Extraction Kit (Beyotime). Protein concentration was quantified by using a Pierce BCA Kit (Thermo Fisher). An aliquot of $20 \mu \mathrm{g}$ total protein was loaded and separated on 10-15\% SDS-PAGE and then, subsequently, electrophoretically transferred onto a polyvinylidene fluoride (PVDF) membrane. The transferred membrane was incubated with primary antibodies at $4^{\circ} \mathrm{C}$ overnight (Table 2) and then incubated with the corresponding secondary antibodies $(1: 1000)$ at room temperature for $1 \mathrm{~h}$. The band was visualized by ECL Detection Reagent (GE Healthcare BioSciences, NJ, USA) in a FluorChem Imaging system (Cell Biosciences, Santa Clara, CA, USA).

2.10. Statistical Analysis. Data are presented as mean \pm standard deviation (SD). To test the difference between groups, one-way analysis of variance (ANOVA) followed by Tukey's post hoc test was performed by using GraphPad Prism 6.0 software (San Diego, CA, USA). Statistical significance was accepted at the level of $p<0.05$.

\section{Results}

3.1. Fatty Acid Composition in Liver Tissues. To measure the effect of fat-1 expression on hepatic fatty acid profile, liver tissues from fat-1 and WT mice were determined by GCMS. Because fat-1 gene can encode n-3 PUFA desaturase that allows converting n-6 PUFA to n-3 PUFA in fat-1 mice, compared with $\mathrm{WT} / \mathrm{CCl}_{4}$ group, liver tissues from fat-1/CCl $\mathrm{CCl}_{4}$ group exhibited higher amounts of n-3 PUFA, including ALA (18:3n-3), EPA (20:5n-3), and DHA (22:6n3 ), and lower levels of n-6 PUFA, mainly linoleic acid (LA, 18:2n-6) and arachidonic acid (AA, 20:4n-6), leading to a remarkable increase in total n-3 PUFA and decreases in total n-6 PUFA and n-6/n-3 ratio (Table 3 ). The level of total saturated fatty acids (SFA) in fat $-1 / \mathrm{CCl}_{4}$ mice was significantly higher, and the level of total monounsaturated fatty acids (MUFAs) tended to be lower. These results demonstrated that the expression of fat-1 gene greatly elevated n-3 PUFA levels in the liver, although both groups were fed the identical diet.

$\mathrm{CCl}_{4}$ exposure also greatly altered the fatty acid composition in the liver. Compared to WT control, the $\mathrm{WT} / \mathrm{CCl}_{4}$ group showed decreased levels in SFA, mainly 14:0, 16:0, and 18:0, and increased levels in MUFA, mainly 16:1 and 18:1, leading to increased ratios of 16:1/16:0 and 18:1/18:0, the fatty acid desaturation index. These findings also suggest that $\mathrm{CCl}_{4}$ challenge may increase the activity or expression of stearoylCoA desaturase-1 (SCD-1).

3.2. Endogenous n-3 PUFA Ameliorates the Features of Acute $\mathrm{CCl}_{4}$-Induced Liver Injury. Liver injury was evaluated by serum enzyme activities and hepatic histopathological changes. ALT and AST are released into the blood once the structural integrity of the hepatocyte was damaged; their levels are the most commonly used markers of liver injury [21]. As shown in Figure 1(a), after acute $\mathrm{CCl}_{4}$ challenge, the serum levels of ALT and AST in WT/CCl 4 group increased 63 and 71 times, respectively, over those in WT group. However, these elevations were significantly blunted in $\mathrm{fat}-1 / \mathrm{CCl}_{4}$ group. The histological changes in the liver were evaluated by $\mathrm{H} \& \mathrm{E}$ staining (Figure 1(b)). WT group exhibited normal architecture 
TABLE 2: Primary antibodies used in immunoblot analysis.

\begin{tabular}{|c|c|c|c|c|}
\hline Primary antibody & Full name & Source & Dilution & Company \\
\hline Bax & BCL2-associated X protein & Rabbit & $1: 1000$ & Cell Signaling Technology \\
\hline Bcl-2 & B-cell lymphoma-2 & Rabbit & $1: 1000$ & Cell Signaling Technology \\
\hline Caspase-3 & Cysteinyl aspartate specific proteinase-3 & Rabbit & $1: 1000$ & Cell Signaling Technology \\
\hline Caspase- 9 & Cysteinyl aspartate specific proteinase- 9 & Rabbit & $1: 1000$ & Cell Signaling Technology \\
\hline CYP2E1 & Cytochrome P4502E1 & Rabbit & $1: 500$ & Abcam \\
\hline Cyto-C & Cytochrome C & Rabbit & $1: 1000$ & Cell Signaling Technology \\
\hline ERK & Extracellular signal-regulated protein kinase & Rabbit & $1: 1000$ & Cell Signaling Technology \\
\hline GADPH & Glyceraldehyde-3-phosphate dehydrogenase & Rabbit & $1: 1000$ & Cell Signaling Technology \\
\hline GCLC & Glutamate cysteine ligase catalytic subunit & Rabbit & $1: 1000$ & Abcam \\
\hline GCLM & Glutamate cysteine ligase modifier subunit & Rabbit & $1: 500$ & Santa Cruz Biotechnology \\
\hline HO-1 & Heme oxygenase-1 & Rabbit & $1: 1000$ & Abcam \\
\hline JNK & c-Jun N-terminal kinase & Rabbit & $1: 1000$ & Cell Signaling Technology \\
\hline Keap1 & Kelch-like ECH-associated protein-1 & Rabbit & $1: 1000$ & Cell Signaling Technology \\
\hline Lamin B & Lamin B & Rabbit & $1: 500$ & Cell Signaling Technology \\
\hline Nrf2 & Nuclear factor erythroid 2-related factor-2 & Rabbit & $1: 1000$ & Santa Cruz Biotechnology \\
\hline NQO1 & NAD(P)H:quinone oxidoreductase-1 & Rabbit & $1: 1000$ & Santa Cruz Biotechnology \\
\hline p38 & p38 mitogen-activated protein kinase & Rabbit & $1: 1000$ & Cell Signaling Technology \\
\hline p62 & Nucleoporin p62 & Rabbit & $1: 1000$ & Cell Signaling Technology \\
\hline p-ERK & Phosphorylated extracellular signal-regulated protein kinase & Rabbit & $1: 1000$ & Cell Signaling Technology \\
\hline p-JNK & Phosphorylated c-Jun N-terminal kinase & Rabbit & $1: 1000$ & Cell Signaling Technology \\
\hline p-p38 & Phosphorylated p38 mitogen-activated protein kinase & Rabbit & $1: 1000$ & Cell Signaling Technology \\
\hline
\end{tabular}

with clear nuclear distribution. $\mathrm{CCl}_{4}$ induced histological changes including severely disrupted hepatic architecture and extensive hepatocellular necrosis around the blood vessels in $\mathrm{WT} / \mathrm{CCl}_{4}$ group, which was reduced in $\mathrm{fat}-1 / \mathrm{CCl}_{4}$ group.

\subsection{Endogenous n-3 PUFA Reduces $\mathrm{CCl}_{4}$-Induced Oxidative} Stress in the Liver. Oxidative stress is characterized as a redox imbalance between prooxidants and endogenous antioxidants, including nonenzymatic antioxidants (e.g., GSH) and enzymatic antioxidants (e.g., SOD, CAT, and GSH-Px) [22]. MDA is an end product of lipid peroxidation (LPO) and has been widely used as a marker of oxidative stress [22]. As shown in Table $4, \mathrm{CCl}_{4}$ exposure induced a remarkable increase of hepatic MDA production by $87.7 \%(2.52 \pm 0.34$ versus $4.73 \pm 0.52, p<0.01$ ), and a remarkable decrease in hepatic lipid peroxidation was observed in $\mathrm{fat}-1 / \mathrm{CCl}_{4}$ group. Conversely, $\mathrm{CCl}_{4}$ challenge depleted endogenous enzymatic and nonenzymatic antioxidants which can protect hepatocytes against oxidative stress, as it is indicated that the activities of SOD, CAT, and GSH-Px and GSH level in $\mathrm{WT} / \mathrm{CCl}_{4}$ group were significantly reduced to $70.5 \%$, $55.7 \%, 59.0 \%$, and $68.4 \%$ of those of WT group, respectively. This depletion of endogenous antioxidants was markedly ameliorated in $\mathrm{fat}-1 / \mathrm{CCl}_{4}$ group. As a radical scavenger, GSH can be oxidized to GSSG under oxidative stress. GSSG is also reduced back to GSH by glutathione reductase (GR). Hence, GSH/GSSG has been also used as a marker of oxidative stress [23]. $\mathrm{CCl}_{4}$ exposure significantly increased the GSSG level and decreased GR activity in the liver, leading to a great decrease in GSH/GSSG ratio; these changes were remarkably ameliorated in fat-1 mice.
3.4. Endogenous n-3 PUFA Upregulates Antioxidant Enzymes via Nuclear Translocation of Nrf2. To understand the underlying molecular mechanisms for the protective effects of endogenous n-3 PUFA against oxidative stress triggered by $\mathrm{CCl}_{4}$, the activation of $\mathrm{Nrf2}$, a main transcription factor regulating antioxidant responses in the liver, was examined by immunofluorescence assay and immunoblot analysis. As shown in Figure 2(a), the significant nuclear translocation of $\mathrm{Nrf} 2$ was detected in $\mathrm{fat}-1 / \mathrm{CCl}_{4}$ group, compared to $\mathrm{WT} / \mathrm{CCl}_{4}$ group, which was in accordance with the results of immunoblot analysis. Endogenous n-3 PUFA in fat-1 mice greatly decreased the protein expression of $\mathrm{Nrf} 2$ in the cytoplasm but increased Nrf2 expression in the nucleus, without changing the level of total Nrf2 expression in the liver (Figure 2(b)). In addition, the Kelch-like ECH-associated protein-1 (Keap1), a repressor protein, and p62, a substrate adaptor sequestosome-1 protein that competes with Nrf2 for binding to Keapl, were examined in the liver by western blot. As shown in Figure 2(c), the lower protein expression of Keapl and higher expression of p62 were detected in fat$1 / \mathrm{CCl}_{4}$ mice compared to $\mathrm{WT} / \mathrm{CCl}_{4}$ group.

Nrf2-regulated genes, such as HO-1, GCLC, GCLM, and NQO1, were also examined. As shown in Figure 3, both mRNA and protein levels of HO-1, GCLC, GCLM, and NQO1 in the liver were obviously upregulated in fat$1 / \mathrm{CCl}_{4}$ group compared to $\mathrm{WT} / \mathrm{CCl}_{4}$ group. Interestingly, $\mathrm{CCl}_{4}$ challenge notably promoted nuclear translocation of Nrf2, elevated Nrf2 expression in the nucleus, and increased the expression of its downstream genes (Figures 2 and 3), which were consistent with the previous studies $[3,4]$. A most plausible explanation is the adaptive cytoprotective 
TABLE 3: Fatty acid composition (\%) of liver tissues.

\begin{tabular}{|c|c|c|c|c|}
\hline \multicolumn{2}{|c|}{ Fatty acids } & \multicolumn{3}{|c|}{$\%$ of total fatty acids } \\
\hline Common name & Symbol & WT & $\mathrm{WT} / \mathrm{CCl}_{4}$ & Fat-1/CCl 4 \\
\hline Lauric acid & $12: 0$ & $0.27 \pm 0.22$ & $0.23 \pm 0.15$ & $0.26 \pm 0.22$ \\
\hline Myristic acid & $14: 0$ & $0.84 \pm 0.28$ & $0.60 \pm 0.13^{\#}$ & $0.76 \pm 0.11^{* *}$ \\
\hline Palmitic acid & $16: 0$ & $28.5 \pm 4.3$ & $24.4 \pm 1.6^{\#}$ & $26.7 \pm 3.8$ \\
\hline Palmitoleic acid & $16: 1$ & $1.16 \pm 0.43$ & $1.59 \pm 0.42^{\#}$ & $1.32 \pm 0.38^{* *}$ \\
\hline Stearic acid & $18: 0$ & $23.0 \pm 7.4$ & $14.5 \pm 2.9^{\# \#}$ & $19.5 \pm 5.4^{*}$ \\
\hline Oleic acid & $18: 1$ & $15.1 \pm 5.0$ & $20.8 \pm 2.3^{\# \#}$ & $17.7 \pm 3.1^{*}$ \\
\hline Linolenic acid & $18: 2,6$ & $17.1 \pm 5.6$ & $24.6 \pm 2.3^{\# \#}$ & $21.3 \pm 4.2^{*}$ \\
\hline$\gamma$-Linolenic acid & $18: 3,6$ & $0.41 \pm 0.20$ & $0.35 \pm 0.10$ & $0.28 \pm 0.16$ \\
\hline$\alpha$-Linolenic acid & $18: 3,3$ & $0.27 \pm 0.05$ & $0.22 \pm 0.05$ & $0.36 \pm 0.07^{* *}$ \\
\hline Arachidic acid & $20: 0$ & $0.45 \pm 0.18$ & $0.23 \pm 0.08^{\# \#}$ & $0.41 \pm 0.12^{* *}$ \\
\hline Eicosenoic acid & $20: 1$ & $0.26 \pm 0.06$ & $0.26 \pm 0.03$ & $0.25 \pm 0.05$ \\
\hline Dihomo- $\gamma$-linoleic acid & $20: 3,6$ & $0.43 \pm 0.14$ & $0.60 \pm 0.10^{\# \#}$ & $0.43 \pm 0.08^{* *}$ \\
\hline Arachidonic acid & $20: 4,6$ & $9.08 \pm 1.48$ & $8.21 \pm 1.86$ & $4.73 \pm 1.29^{* *}$ \\
\hline Eicosapentaenoic acid & $20: 5,3$ & $0.03 \pm 0.02$ & $0.04 \pm 0.03$ & $0.42 \pm 0.16^{* *}$ \\
\hline Behenic acid & $22: 0$ & $0.17 \pm 0.05$ & $0.15 \pm 0.05$ & $0.17 \pm 0.01$ \\
\hline Erucic acid & $22: 1$ & $0.20 \pm 0.06$ & $0.18 \pm 0.11$ & $0.29 \pm 0.08^{*}$ \\
\hline Docosadienoic acid & $22: 2,6$ & $0.25 \pm 0.10$ & $0.10 \pm 0.11^{\# \#}$ & $0.02 \pm 0.01^{*}$ \\
\hline Docosatetraenoic acid & $22: 4,6$ & $0.28 \pm 0.16$ & $0.45 \pm 0.12^{\# \#}$ & $0.22 \pm 0.10^{* *}$ \\
\hline Docosapentaenoic acid & $22: 5,3$ & $0.04 \pm 0.03$ & $0.07 \pm 0.06$ & $0.15 \pm 0.21$ \\
\hline Lignoceric acid & $24: 0$ & $0.02 \pm 0.01$ & $0.02 \pm 0.02$ & $0.01 \pm 0.01$ \\
\hline Docosahexaenoic acid & $22: 6,3$ & $1.67 \pm 0.39$ & $1.94 \pm 0.33$ & $4.16 \pm 1.17^{* *}$ \\
\hline Nervonic acid & $24: 1$ & $0.09 \pm 0.04$ & $0.20 \pm 0.09^{\# \#}$ & $0.13 \pm 0.09$ \\
\hline SFAs & & $53.5 \pm 11.9$ & $40.4 \pm 4.1^{\# \#}$ & $48.1 \pm 9.1^{* *}$ \\
\hline MUFAs & & $16.9 \pm 5.5$ & $23.1 \pm 2.7^{\# \#}$ & $19.8 \pm 3.6^{*}$ \\
\hline n-3 PUFAs & & $2.04 \pm 0.38$ & $2.30 \pm 0.33$ & $5.1 \pm 1.4^{* *}$ \\
\hline n-6 PUFAs & & $27.5 \pm 6.5$ & $34.3 \pm 2.8$ & $27.0 \pm 5.6^{*}$ \\
\hline Total PUFAs & & $29.6 \pm 6.8$ & $36.6 \pm 3.0$ & $32.2 \pm 6.8$ \\
\hline n-6/n-3 PUFAs & & $13.4 \pm 1.5$ & $15.1 \pm 1.7$ & $5.40 \pm 0.75^{* *}$ \\
\hline $16: 1 / 16: 0$ & & $0.04 \pm 0.02$ & $0.07 \pm 0.02^{\# \#}$ & $0.05 \pm 0.02$ \\
\hline 18:1/18:0 & & $0.80 \pm 0.52$ & $1.51 \pm 0.42^{\# \#}$ & $1.01 \pm 0.41^{* *}$ \\
\hline
\end{tabular}

Values are expressed as the means $\pm \mathrm{SD}(n=10) ;{ }^{\#} p<0.05$ and ${ }^{\# \#} p<0.01$ versus WT group; ${ }^{*} p<0.05$ and ${ }^{* *} p<0.01$ versus WT/CCl group. $^{\text {SFA: }}$ saturated fatty acid; MUFA: monounsaturated fatty acid; PUFA: polyunsaturated fatty acid.

reaction of organisms in response to oxidative stimuli. These results demonstrate that the protection of endogenous $n-3$ PUFA against $\mathrm{CCl}_{4}$-induced liver damage is correlated with ameliorating oxidative stress in the liver via activating Nrf2 and upregulating its downstream genes.

3.5. Endogenous n-3 PUFA Reduces Hepatocyte Apoptosis via Regulating MAPK Signal Pathway. As cell apoptosis directly reflects the extent of liver injury caused by $\mathrm{CCl}_{4}$, a TUNEL assay was conducted to estimate the regulation of cell apoptosis by endogenous n-3 PUFA. As shown in Figure 4(a), after $24 \mathrm{~h}$ of $\mathrm{CCl}_{4}$ challenge, the number of TUNEL-positive cells in the liver section was significantly increased over the WT control group. In fat-1/ $\mathrm{CCl}_{4}$ group, this increase in apoptotic cells was significantly decreased. In addition, during the $\mathrm{CCl}_{4}$-induced liver injury, there was a cascade of apoptosisrelated molecular events $[24,25]$. After $\mathrm{CCl}_{4}$ challenge, the protein expressions of the proapoptotic proteins, including cytochrome C, caspase-3, caspase-9, and Bax, were obviously increased in liver tissues from WT mice, while the levels of the antiapoptotic factor Bcl-2 was significantly decreased. In agreement with the reduction of TUNEL-positive cells, compared with $\mathrm{WT} / \mathrm{CCl}_{4}$ mice, the fat-1/CCl $\mathrm{CC}_{4}$ mice showed decreased levels of the aforementioned proapoptotic proteins and increased level of Bax in the liver, as indicated by western blot analyses (Figure 4(b)). These results indicate that endogenous n-3 PUFA effectively prevents $\mathrm{CCl}_{4}$-induced DNA fragmentation.

To understand the underlying molecular mechanisms for the inhibitory effects of endogenous n-3 PUFA on $\mathrm{CCl}_{4}$ induced hepatocyte apoptosis, ERK, JNK, and p38, the major components in mitogen-activated protein kinase (MAPK) pathways, which are critical regulators of cell proliferation and death in response to diverse stresses, were examined by immunoblotting. Oxidative stress in the liver activates MAPK after $\mathrm{CCl}_{4}$ challenge and results in activation of JNK, p38, and 

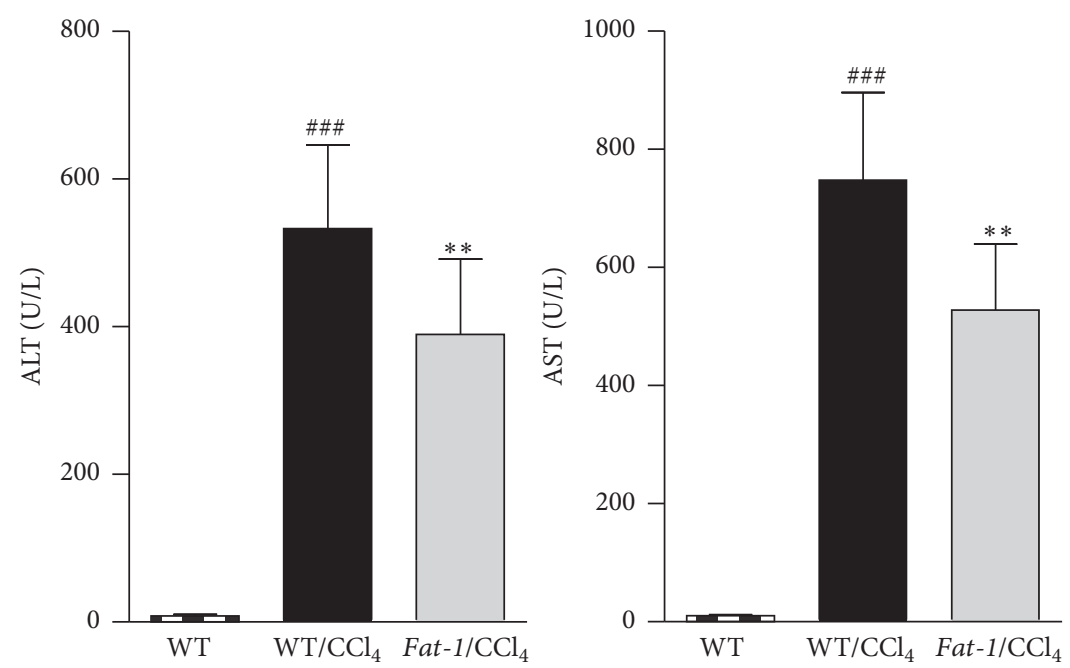

(a)
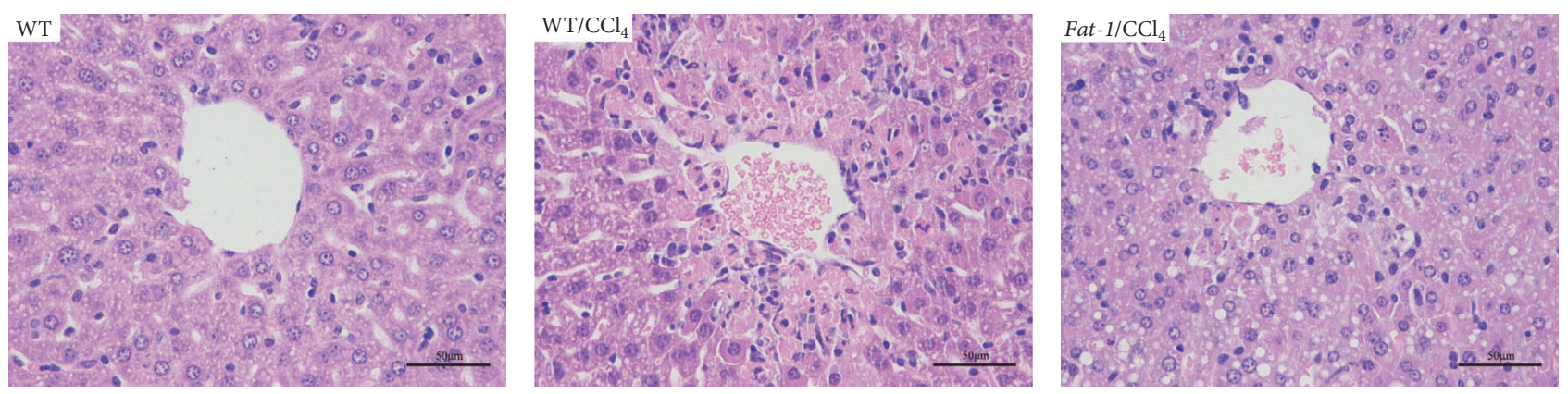

(b)

FIGURE 1: Endogenous n-3 PUFA alleviates $\mathrm{CCl}_{4}$-induced acute liver injury in fat-1 mice. (a) Plasma levels of alanine aspartate transaminase (AST) and aminotransferase (ALT). (b) Representative hematoxylin and eosin (H\&E) staining of liver tissue sections (magnification: 400x). Values represent the means $\pm \mathrm{SD}(n=10) ;{ }^{\# \# \#} p<0.001$ versus WT group; ${ }^{* *} p<0.01$ versus $\mathrm{WT} / \mathrm{CCl}_{4}$ group.

TABLE 4: Effects of endogenous omega-3 fatty acids on oxidative stress parameters in the liver.

\begin{tabular}{lccc}
\hline Parameters & WT & WT/CCl & Fat-1/CCl \\
\hline MDA (nmol/mg protein) & $2.52 \pm 0.34$ & $4.73 \pm 0.52^{\# \#}$ & $3.99 \pm 0.54^{* *}$ \\
SOD (U/mg protein) & $303.8 \pm 33.8$ & $214.3 \pm 32.8^{\#}$ & $261.8 \pm 44.2^{* *}$ \\
CAT (U/mg protein) & $13.5 \pm 1.9$ & $7.52 \pm 2.26^{\#}$ & $9.97 \pm 2.10^{*}$ \\
GSH-Px (U/mg protein) & $975.6 \pm 317.2$ & $565.4 \pm 199.1^{\# \#}$ & $770.1 \pm 283.4^{* *}$ \\
GR (U/g protein) & $10.6 \pm 1.7$ & $6.22 \pm 1.77^{\# \#}$ & $7.92 \pm 1.72^{*}$ \\
GSH (mg/g protein) & $11.6 \pm 1.8$ & $7.96 \pm 0.89^{\# \#}$ & $9.27 \pm 1.93^{* *}$ \\
GSSG (mg/g protein) & $1.26 \pm 0.36$ & $2.29 \pm 0.56^{\# \#}$ & $1.72 \pm 0.40^{*}$ \\
GSH/GSSG (fold) & $9.72 \pm 2.27$ & $3.62 \pm 0.89^{\# \#}$ & $5.46 \pm 0.94^{* *}$ \\
\hline
\end{tabular}

Data are expressed as mean $\pm \mathrm{SD}(n=10) .{ }^{\#} p<0.05$ and $^{\# \#} p<0.01$ versus WT group; ${ }^{*} p<0.05$ and ${ }^{* *} p<0.01$ versus WT/CCl group. $^{*}$

ERK [25]. As shown in Figure 4(c), $\mathrm{CCl}_{4}$ exposure obviously increased the phosphorylated protein levels of JNK, p38, and ERK1/2, without changing their total expressions in liver tissues from WT mice. These increases in phosphorylated kinases were all downregulated by endogenous n-3 PUFA in fat-1 mice. Thus, protective effects of endogenous n-3 PUFA against $\mathrm{CCl}_{4}$-induced hepatocyte apoptosis are associated with suppressing MAPK pathways.

\section{Discussion}

In this study, we used fat- 1 transgenic mice to investigate the role of endogenous n-3 PUFA in $\mathrm{CCl}_{4}$-caused acute liver damage. We demonstrate that $\mathrm{CCl}_{4}$ challenge caused severe liver injury in WT mice, as illustrated by markedly elevated serum activities of AST and ALT, oxidative stress, and hepatocyte apoptosis. Those pathological alterations 

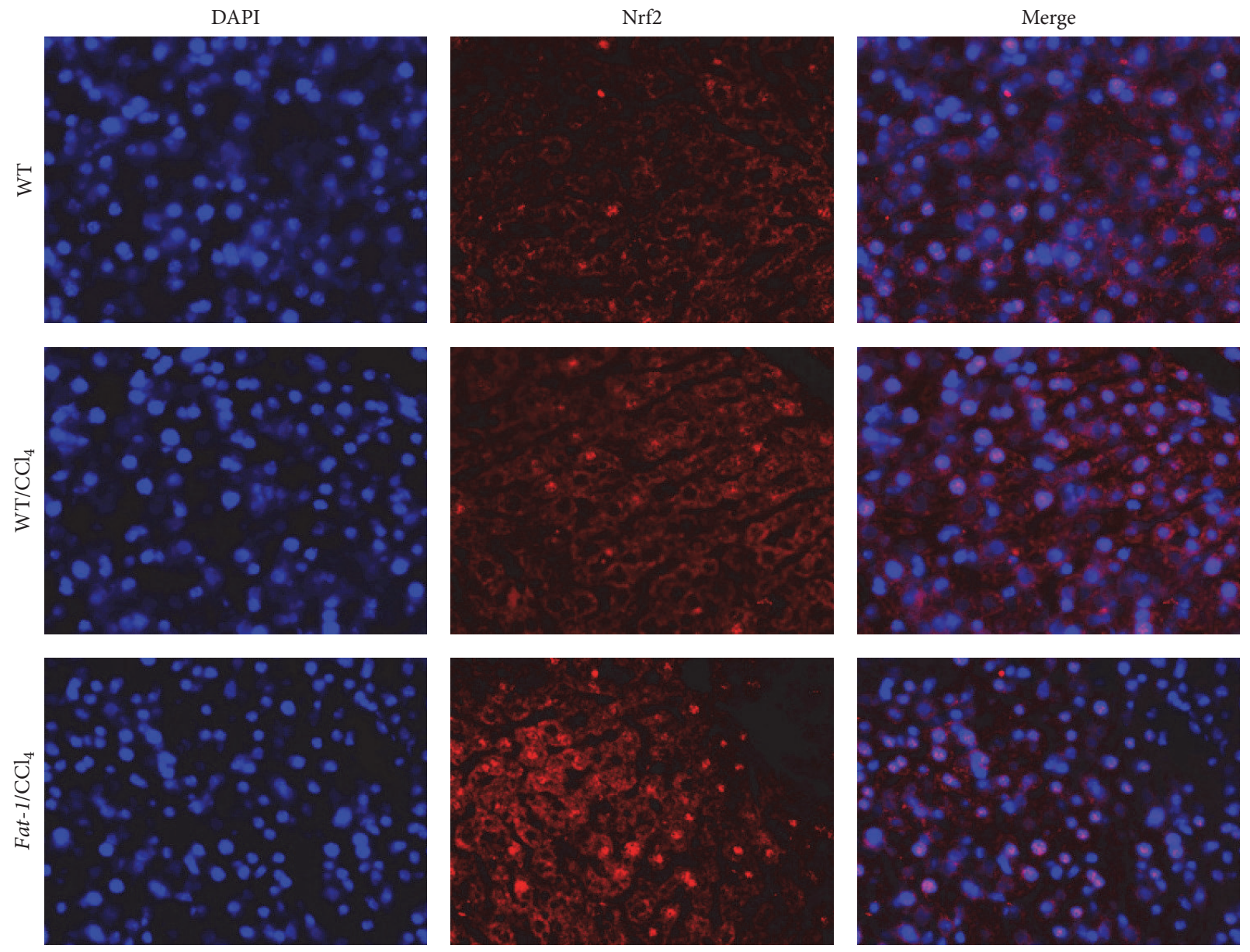

(a)

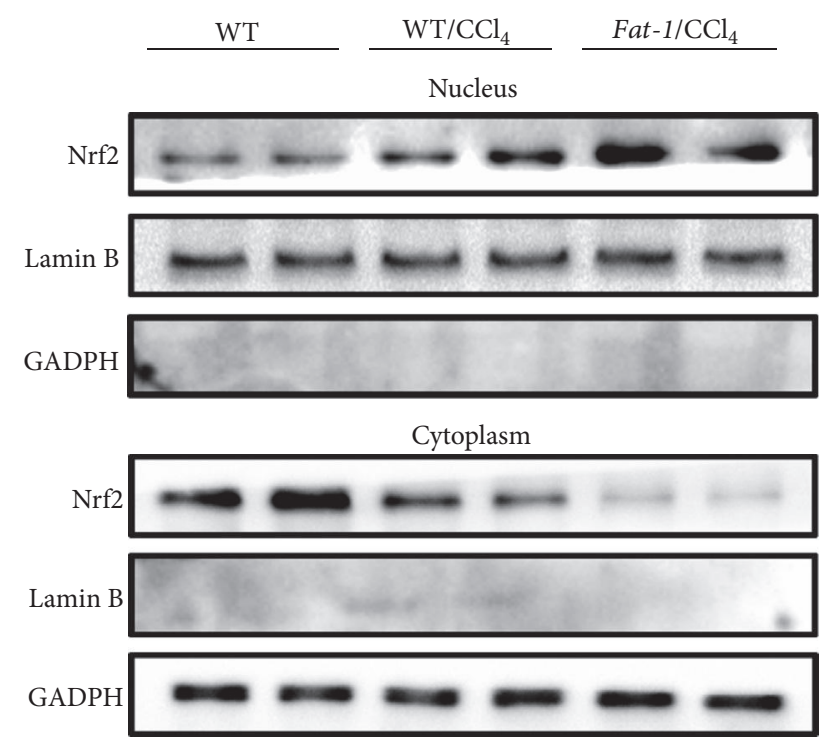

(b)

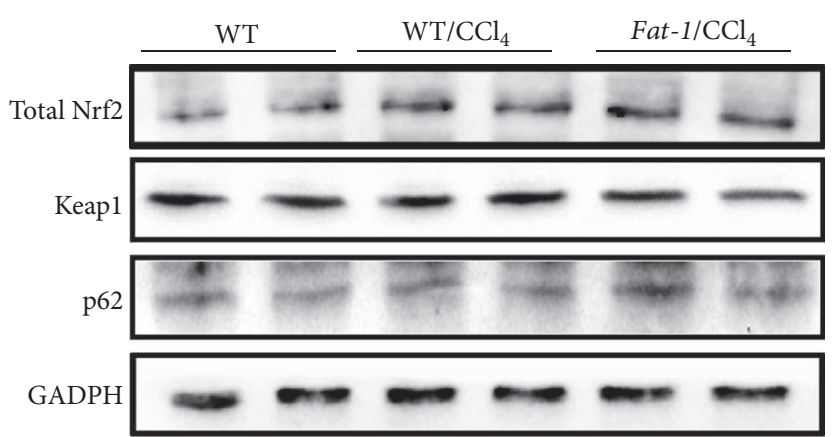

(c)

FIGURE 2: Endogenous n-3 PUFA induces nuclear translocation of Nrf2. (a) Immunofluorescence staining of Nrf2. (b) Western blot analysis of Nrf2 in the nucleus and cytoplasm. (c) Western blot analysis of total Nrf2, keap1, and p62 in liver tissue. 


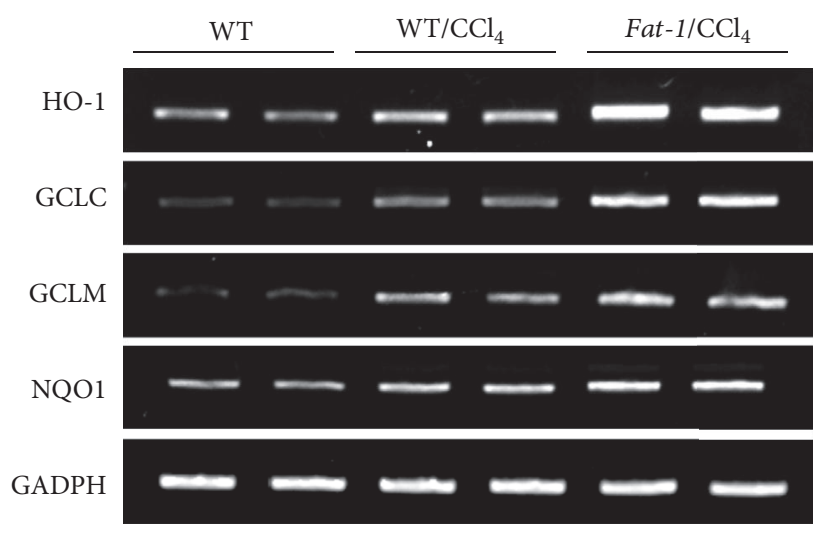

(a)

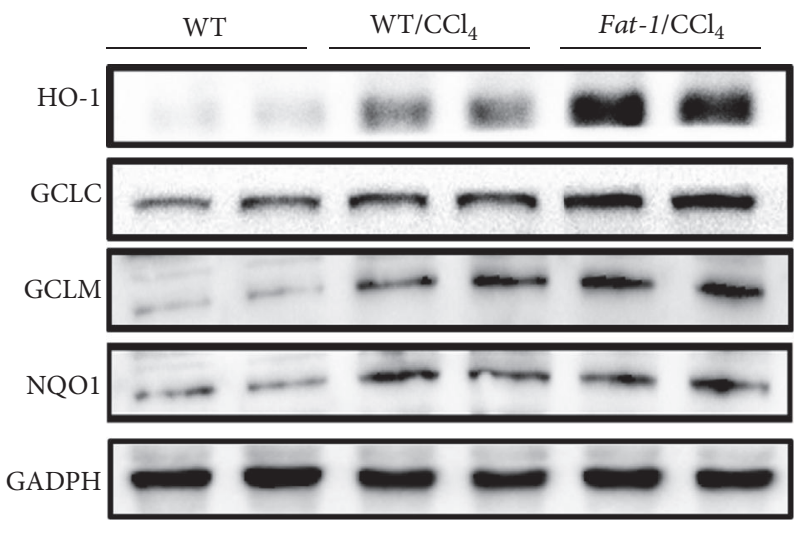

(b)

FIgURE 3: Endogenous n-3 PUFA upregulates mRNA (a) and protein (b) expressions of Nrf2 target genes, including HO-1, GCLC, GCLM, and NQO1.

were remarkably relieved in fat-1 mice after $\mathrm{CCl}_{4}$ challenge, which was associated with activating Nrf2 and regulating MAPK signal pathway.

The fat-1 transgenic mice have been widely used as a novel tool for investigating the benefits of long chain n-3 PUFAs and the mechanisms underlying their actions [26]. Fat-1 transgenic mice, carrying a fat-1 gene from C. elegans, encode a desaturase that can convert n-3 to n-6 PUFA, resulting in abundant n-3 PUFA, without changing total PUFA in their organs and tissues (Table 3). Fat-1 mice and WT littermates endogenously generate distinct fatty acid profiles in the liver while feeding them the same diet rich in n-6 PUFA. Thus, several variables arising from different diets, such as flavor, oxidation degree, and unwanted components of fat used, may be well avoided [15]. As expected, in this study, liver tissues from $\mathrm{fat}-1 / \mathrm{CCl}_{4}$ group exhibited higher amounts of n-3 PUFA, particularly EPA and DHA, and lower level of n-6 PUFA, leading to a remarkable increase in total n-3 PUFA in the liver, compared to $\mathrm{WT} / \mathrm{CCl}_{4}$ group. As a wellcharacterized animal model, the fat 1 mice were studied to examine the impacts of endogenous n-3 PUFA on $\mathrm{CCl}_{4}$ induced acute liver injury.

Oxidative stress is critical during the pathogenesis of $\mathrm{CCl}_{4}$-induced acute liver injury [27]. $\mathrm{CCl}_{4}$ challenge produces highly reactive species and increases cellular production of ROS and MDA, leading to oxidative stress in tissues, especially the liver where it is primarily metabolized [6]. Additionally, $\mathrm{CCl}_{4}$-induced oxidative stress also depletes antioxidant defense system, including endogenous nonenzymatic (e.g., GSH) and enzymatic (e.g., SOD, CAT, GSH-Px, and GR) antioxidants. GSH has been considered to be the first line of defense against free radicals. It was documented that GSH is an important antioxidant in eliminating toxic free radicals and reactive toxic $\mathrm{CCl}_{4}$ metabolites [28, 29]. The sulfhydryl residues of GSH molecule are easily oxidized to GSSG, which can be reduced back to GSH by GR [30]. Thus, GSH/GSSG ratio serves as a reliable marker to evaluate the redox status and potential of oxidative stress [30]. In our study, $\mathrm{CCl}_{4}$ challenge increased hepatic MDA and GSSG and the ratio of GSH/GSSG and depleted GSH, SOD, CAT, GSH$\mathrm{Px}$, and GR in livers of WT mice, which was ameliorated in fat-1 mice after $\mathrm{CCl}_{4}$ treatment (Table 4 ). To examine how n-3 PUFA improves the antioxidant defense system, the nuclear translocation of Nrf2 and the expressions of Nrf2 target genes in the liver were evaluated. Nrf2 acts as a transcription factor which plays a key role in regulating the expression of antioxidant proteins in response to oxidative stress [31]. Under physiological condition, Nrf2 is attached to Keap1, a specific repressor, in the cytoplasm, which promotes Nrf2 degradation by the ubiquitin proteasome pathway [32]. In the presence of ROS, Nrf2 degradation ceases, while stabilized Nrf2 translocates into the nucleus, which triggers the expression of a series of antioxidants, including HO-1, GCLC, GCLM, and NQO1, through antioxidant response element (ARE). HO-1 is a strong antioxidant with antiapoptotic and anti-inflammatory effects in the liver. GCLC and GCLM are key rate-limiting enzymes in GSH biosynthesis [33]. p62 is a substrate adaptor sequestosome-1 protein that modulates the Nrf2-Keap1 signaling pathway by competing with Nrf2 for binding to Keapl. In this study, the significant nuclear translocation of $\mathrm{Nrf} 2$ was observed in fat-1/CCl 4 group, as evidenced by immunofluorescence assay and immunoblot analysis (Figure 2). Additionally, fat-1/CCl 4 mice showed lower protein expression of Keapl and higher expressions of p62, HO-1, GCLC, GCLM, and NQO1 in the liver, when compared to $\mathrm{WT} / \mathrm{CCl}_{4}$ mice (Figure 3 ). These results suggest that the protective effects of endogenous n-3 PUFA against $\mathrm{CCl}_{4}$-caused acute liver damage might be attributable to reducing oxidative stress via the activation of Nrf2-keap1 pathway.

The induction of hepatocyte apoptosis has been well studied in acute liver injury induced by $\mathrm{CCl}_{4}$ exposure [34]. Our data demonstrated that $\mathrm{CCl}_{4}$ challenge markedly induced hepatocyte apoptosis in WT mice (Figure 4(a)), which was significantly reduced in fat-1 mice after $\mathrm{CCl}_{4}$ exposure. The mitochondrial apoptotic pathway was considered to be involved in various types of cellular stress [35]. Oxidative stress causes elevated cytochrome $\mathrm{C}$ in the cytoplasm 
DAPI
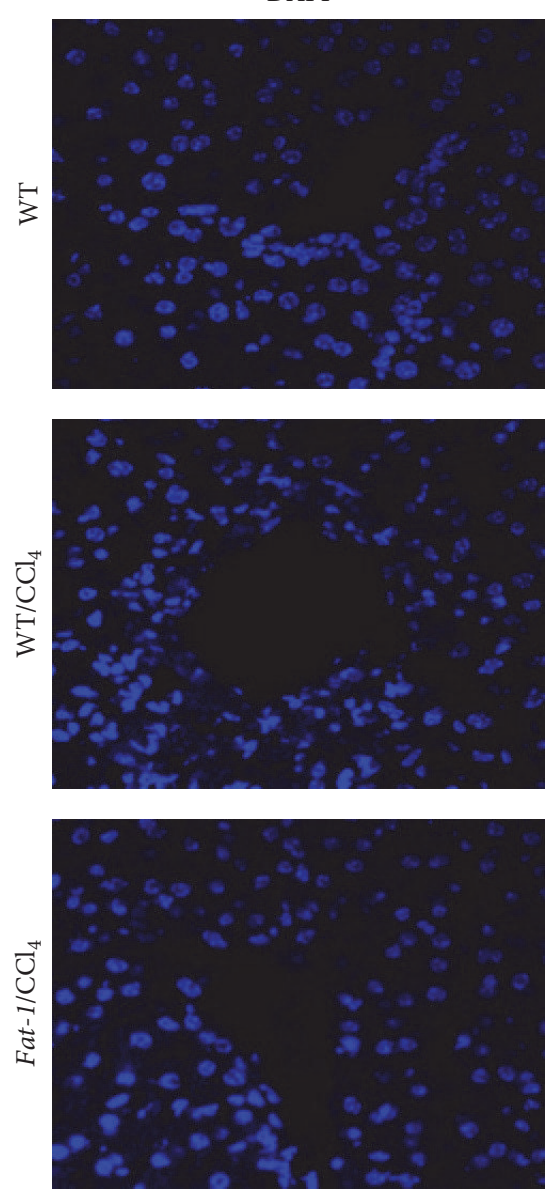

(a)

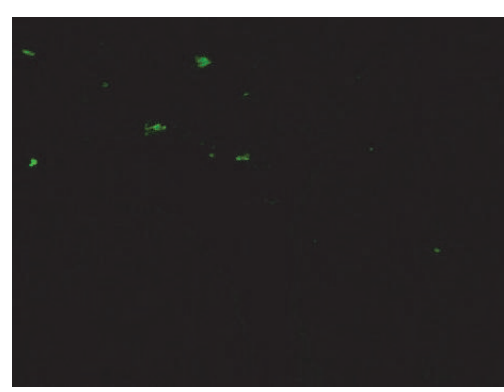

TUNEL
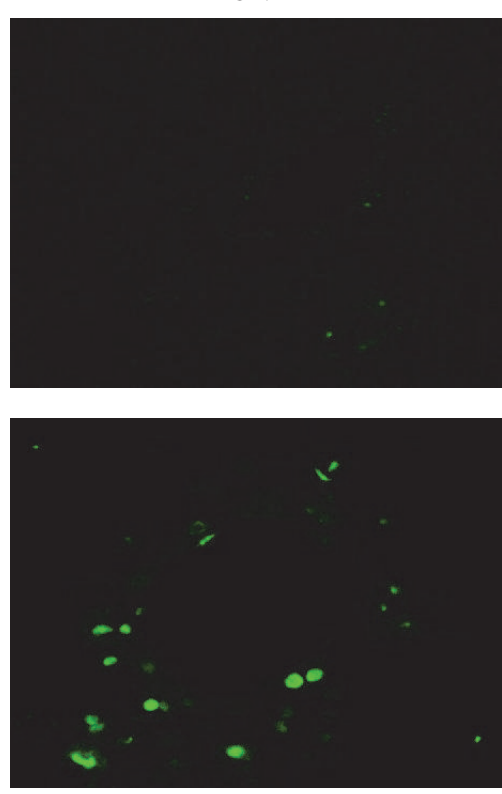
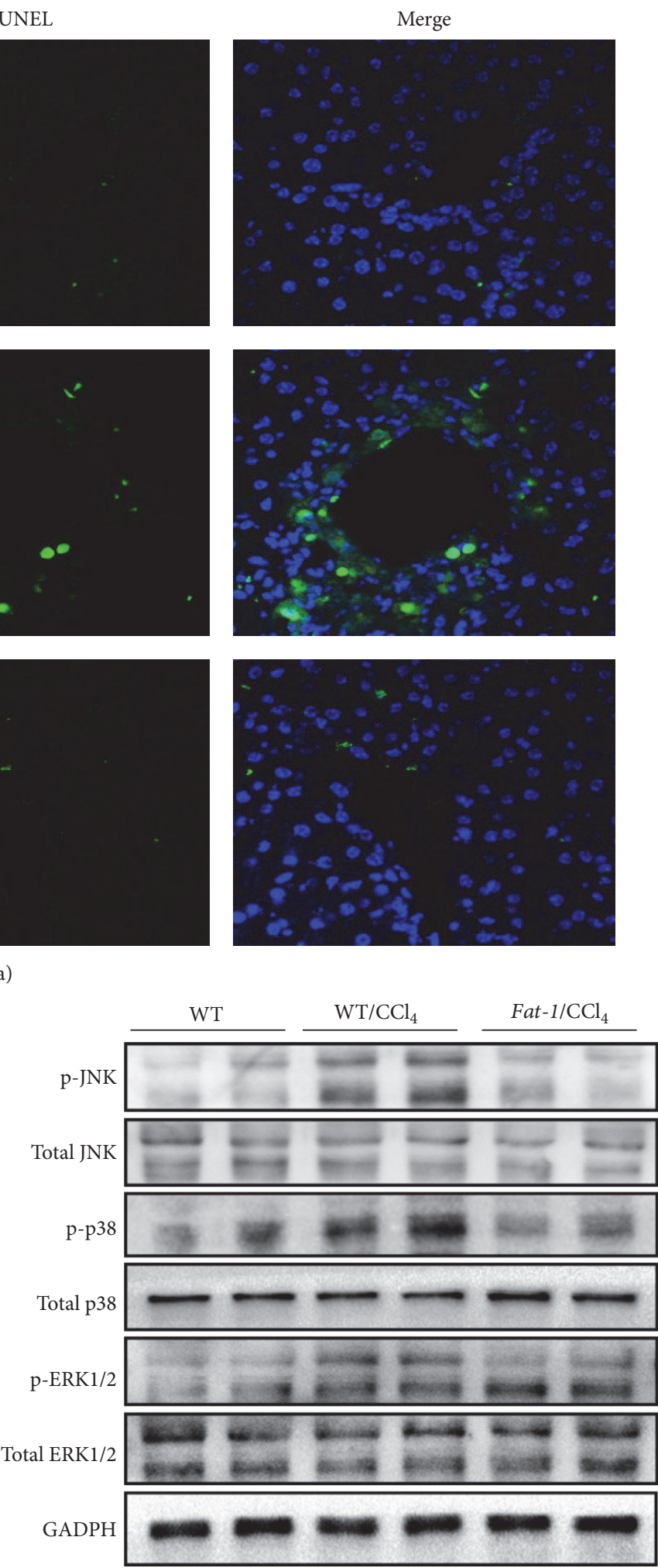

(c)

FIGURE 4: Endogenous n-3 PUFA protects against $\mathrm{CCl}_{4}$-induced hepatocyte apoptosis in fat-1 mice via regulating MAPK signaling pathway. (a) Representative images of TUNEL stained liver sections (magnification: 200x): green fluorescence indicates the positive cells, and cellular nucleus is labeled by staining DAPI with blue fluorescence. (b) Western blot analysis of apoptosis-related proteins, including cytochrome C, caspase-3, caspase-9, Bcl-2, and Bax. (c) Western blot analysis of total and phosphorylated protein expression of JNK, p38, and ERK. 


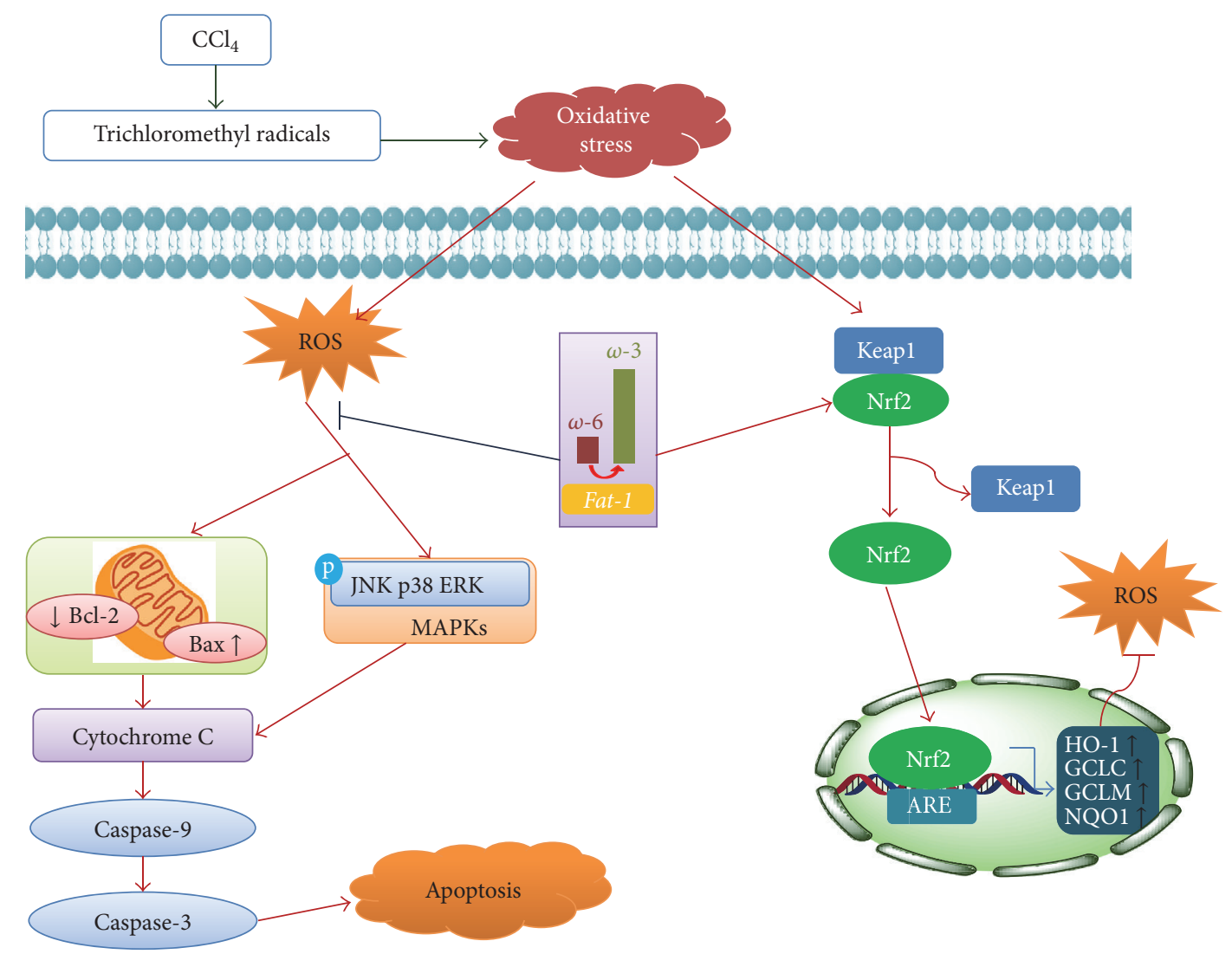

FIGURE 5: A schematic diagram of the potential mechanisms that underlie the protective effects of n-3 PUFA against $\mathrm{CCl}_{4}$-induced acute liver injury.

which is released from the mitochondria, which consequently induces the activation of caspase cascades, including caspase3 and caspase-9. The mitochondrial apoptotic pathway is also regulated by several apoptosis-related factors, such as $\mathrm{Bax}$ and $\mathrm{Bcl}-2$ [36]. The ratio of proapoptotic protein Bax to antiapoptotic protein $\mathrm{Bcl}-2$ is critical for cell death or survival. Increased $\mathrm{Bax} / \mathrm{Bcl}-2$ ratio leads to cytochrome $\mathrm{C}$ release, caspase-3 activation, and eventually apoptosis [37]. Our data revealed that endogenous n-3 PUFA significantly inhibited the upregulation of cytochromeC, caspase-3, caspase-9, and Bax and normalized the downregulation of Bcl-2 expression induced by $\mathrm{CCl}_{4}$ (Figure 4(b)), which was well consistent with TUNEL staining results.

The MAPK family members, including JNK, p38, and JNK, are crucial for the regulation of cell proliferation, differentiation, apoptosis, and cellular responses to oxidative stress $[38,39]$. Activated MAPKs can inactivate Bcl-2 by phosphorylation, activate caspase- 9 , and regulate the release of cytochrome C from the mitochondria [40]. Previous studies revealed that suppressing protein expressions of the phosphorylated MAPK members contributed to the inhibition of $\mathrm{CCl}_{4}$-induced apoptosis $[38,39]$. In this study, the upregulation of phosphorylated JNK, p38, and JNK induced by $\mathrm{CCl}_{4}$ challenge was attenuated in the livers of fat-1 mice. These findings suggest that reducing hepatocyte apoptosis via suppressing MAPK pathway might also contribute to the inhibitory function of n-3 PUFA on $\mathrm{CCl}_{4}$-induced liver injury.

In conclusion, endogenous n-3 PUFA effectively ameliorated $\mathrm{CCl}_{4}$-induced acute liver injury, and this protective effect might be associated with ameliorating oxidative stress via Nrf2 activation and reducing apoptosis via suppression of MAPK pathway, as illustrated in Figure 5. Our findings suggest that dietary supplement with n-3 PUFA may be beneficial for the prevention of liver injury.

\section{Abbreviations}

ALT: $\quad$ Alanine transaminase

ARE: Antioxidant response element

AST: Aspartate transaminase

Bax: $\quad$ Bcl-2-associated $\mathrm{X}$ protein

Bcl-2: B-cell lymphoma-2

CAT: Catalase

Caspase-3: Cysteinyl aspartate specific proteinase-3

Caspase-9: Cysteinyl aspartate specific proteinase-9

$\mathrm{CCl}_{4}$ : $\quad$ Carbon tetrachloride

CYP2E1: Cytochrome P4502E1

Cyto-C: Cytochrome C

DAPI: 4,6-Diamidino-2-phenylindole

ERK: $\quad$ Extracellular signal-regulated kinase

FAME: Fatty acid methyl esters 
GADPH: Glyceraldehyde-3-phosphate dehydrogenase

GCLC: Glutamate cysteine ligase catalytic subunit

GCLM: Glutamate cysteine ligase modifier subunit

GSH: $\quad$ Reduced glutathione

GSH-Px: Glutathione peroxidase

GSSG: Oxidized glutathione

H\&E: $\quad$ Hematoxylin and eosin

HO-1: Heme oxygenase-1

JNK: c-Jun N-terminal kinase

Keapl: $\quad$ Kelch-like ECH-associated protein-1

MAPK: Mitogen-activated protein kinase

MDA: Malondialdehyde

MUFA(s): Monounsaturated fatty acid(s)

Nrf2: Nuclear factor-erythroid 2-related factor-2

NQO1: $\quad \mathrm{NAD}(\mathrm{P}) \mathrm{H}$ :quinone oxidoreductase-1

PUFA(s): Polyunsaturated fatty acid(s)

p62: $\quad$ Nucleoporin p62

ROS: $\quad$ Reactive oxygen species

SFA(s): Saturated fatty acid(s)

SOD: $\quad$ Superoxide dismutase

TUNEL: Terminal deoxynucleotidyl transferasemediated deoxyuridine 5-triphosphate nick end labeling

WT: Wild-type.

\section{Competing Interests}

The authors declare that there are no competing interests.

\section{Acknowledgments}

The present study was supported by grants from the Research Committee of the University of Macau (MYRG111-ICMS13 to Jian-Bo Wan) and from Macao Science and Technology Development Fund (010/2013/A1 to Jian-Bo Wan).

\section{References}

[1] L. Qu, H. Xin, G. Zheng, Y. Su, and C. Ling, "Hepatoprotective activity of the total saponins from Actinidia valvata dunn root against carbon tetrachloride-induced liver damage in mice," Evidence-Based Complementary and Alternative Medicine, vol. 2012, Article ID 216061, 13 pages, 2012.

[2] R. N. Jadeja, N. H. Urrunaga, S. Dash, S. Khurana, and N. K. Saxena, "Withaferin-a reduces acetaminophen-induced liver injury in mice," Biochemical Pharmacology, vol. 97, no. 1, pp. 122-132, 2015.

[3] D. Dong, L. Xu, L. Yin, Y. Qi, and J. Peng, "Naringin prevents carbon tetrachloride-induced acute liver injury in mice," Journal of Functional Foods, vol. 12, pp. 179-191, 2015.

[4] C. Su, X. Xia, Q. Shi et al., "Neohesperidin dihydrochalcone versus $\mathrm{CCl}_{4}$-induced hepatic injury through different mechanisms: the implication of free radical scavenging and Nrf2 Activation," Journal of Agricultural and Food Chemistry, vol. 63, no. 22, pp. 5468-5475, 2015.

[5] A. F. Ismail, A. A. Salem, and M. M. Eassawy, "Hepatoprotective effect of grape seed oil against carbon tetrachloride induced oxidative stress in liver of $\gamma$-irradiated rat," Journal of Photochemistry and Photobiology B: Biology, vol. 160, pp. 1-10, 2016.
[6] G. M. Campo, A. Avenoso, S. Campo et al., "Hyaluronic acid and chondroitin-4-sulphate treatment reduces damage in carbon tetrachloride-induced acute rat liver injury," Life Sciences, vol. 74, no. 10, pp. 1289-1305, 2004.

[7] B. O. Cho, H. W. Ryu, C. H. Jin et al., "Blackberry extract attenuates oxidative stress through up-regulation of Nrf2dependent antioxidant enzymes in carbon tetrachloride-treated rats," Journal of Agricultural and Food Chemistry, vol. 59, no. 21, pp. 11442-11448, 2011.

[8] Y.-F. Lu, J. Liu, K. C. Wu, Q. Qu, F. Fan, and C. D. Klaassen, "Overexpression of Nrf2 protects against microcystin-induced hepatotoxicity in mice," PLoS ONE, vol. 9, no. 3, Article ID e93013, 2014.

[9] E. Scorletti, L. Bhatia, K. G. Mccormick et al., "Effects of purified eicosapentaenoic and docosahexaenoic acids in nonalcoholic fatty liver disease: Results from the WELCOME* study," Hepatology, vol. 60, no. 4, pp. 1211-1221, 2014.

[10] E. M. Tillman and R. A. Helms, "Omega-3 long chain polyunsaturated Fatty acids for treatment of parenteral nutritionassociated liver disease: a review of the literature," The Journal of Pediatric Pharmacology and Therapeutics, vol. 16, pp. 31-38, 2011.

[11] M. Wang, X. Zhang, C. Yan et al., "Preventive effect of $\alpha$ linolenic acid-rich flaxseed oil against ethanol-induced liver injury is associated with ameliorating gut-derived endotoxinmediated inflammation in mice," Journal of Functional Foods, vol. 23, pp. 532-541, 2016.

[12] M. Wang, X. Zhang, K. Feng et al., "Dietary $\alpha$-linolenic acidrich flaxseed oil prevents against alcoholic hepatic steatosis via ameliorating lipid homeostasis at adipose tissue-liver axis in mice," Scientific Reports, vol. 6, p. 26826, 2016.

[13] L. L. Huang, J. B. Wan, B. Wang et al., "Suppression of acute ethanol-induced hepatic steatosis by docosahexaenoic acid is associated with downregulation of stearoyl-CoA desaturase 1 and inflammatory cytokines," Prostaglandins Leukotrienes and Essential Fatty Acids, vol. 88, no. 5, pp. 347-353, 2013.

[14] C. Schmöcker, K. H. Weylandt, L. Kahlke et al., "Omega3 fatty acids alleviate chemically induced acute hepatitis by suppression of cytokines," Hepatology, vol. 45, no. 4, pp. 864869, 2007.

[15] J.-B. Wan, L.-L. Huang, R. Rong, R. Tan, J. Wang, and J. X. Kang, "Endogenously decreasing tissue n-6/n-3 fatty acid ratio reduces atherosclerotic lesions in apolipoprotein E-deficient mice by inhibiting systemic and vascular inflammation," Arteriosclerosis, Thrombosis, and Vascular Biology, vol. 30, no. 12, pp. 2487-2494, 2010.

[16] J. X. Kang, J. Wang, L. Wu, and Z. B. Kang, "Transgenic mice: fat-1 mice convert n-6 to n-3 fatty acids," Nature, vol. 427, no. 6974, p. 504, 2004.

[17] H. Xu, T. Guo, Y.-F. Guo et al., "Characterization and protection on acute liver injury of a polysaccharide MP-I from Mytilus coruscus," Glycobiology, vol. 18, no. 1, pp. 97-103, 2008.

[18] X.-J. Zhang, L.-L. Huang, X.-J. Cai, P. Li, Y.-T. Wang, and J.-B. Wan, "Fatty acid variability in three medicinal herbs of Panax species," Chemistry Central Journal, vol. 7, no. 1, article 12, 2013.

[19] X.-J. Zhang, L.-L. Huang, H. Su et al., "Characterizing plasma phospholipid fatty acid profiles of polycystic ovary syndrome patients with and without insulin resistance using GC-MS and chemometrics approach," Journal of Pharmaceutical and Biomedical Analysis, vol. 95, pp. 85-92, 2014.

[20] G.-J. Huang, J.-S. Deng, S.-S. Huang, Y.-Y. Shao, C.-C. Chen, and Y.-H. Kuo, "Protective effect of antrosterol from 
Antrodia camphorata submerged whole broth against carbon tetrachloride-induced acute liver injury in mice," Food Chemistry, vol. 132, no. 2, pp. 709-716, 2012.

[21] R.-B. Ding, K. Tian, L.-L. Huang et al., "Herbal medicines for the prevention of alcoholic liver disease: a review," Journal of Ethnopharmacology, vol. 144, no. 3, pp. 457-465, 2012.

[22] R.-B. Ding, K. Tian, Y.-W. Cao et al., "Protective effect of Panax notoginseng saponins on acute ethanol-induced liver injury is associated with ameliorating hepatic lipid accumulation and reducing ethanol-mediated oxidative stress," Journal of Agricultural and Food Chemistry, vol. 63, no. 9, pp. 2413-2422, 2015.

[23] Y.-T. Tung, J.-H. Wu, C.-C. Huang et al., "Protective effect of Acacia confusa bark extract and its active compound gallic acid against carbon tetrachloride-induced chronic liver injury in rats," Food and Chemical Toxicology, vol. 47, no. 6, pp. 13851392, 2009.

[24] X.-J. Zhang, C. He, P. Li, H. Su, and J.-B. Wan, "Ginsenoside Rgl, a potential JNK inhibitor, protects against ischemia/reperfusion-induced liver damage," Journal of Functional Foods, vol. 15, pp. 580-592, 2015.

[25] H.-Y. Kim, J. Park, K.-H. Lee et al., "Ferulic acid protects against carbon tetrachloride-induced liver injury in mice," Toxicology, vol. 282, no. 3, pp. 104-111, 2011.

[26] J. X. Kang, "Fat-1 transgenic mice: a new model for omega-3 research," Prostaglandins Leukotrienes and Essential Fatty Acids, vol. 77, no. 5-6, pp. 263-267, 2007.

[27] J.-C. Lin, Y.-J. Peng, S.-Y. Wang et al., "Sympathetic nervous system control of carbon tetrachloride-induced oxidative stress in liver through $\alpha$-adrenergic signaling," Oxidative Medicine and Cellular Longevity, vol. 2016, Article ID 3190617, 11 pages, 2016.

[28] G. Ray and S. A. Husain, "Oxidants, antioxidants and carcinogenesis," Indian Journal of Experimental Biology, vol. 40, no. 11, pp. 1213-1232, 2002.

[29] M. Boll, L. W. Weber, E. Becker, and A. Stampfl, "Mechanism of carbon tetrachloride-induced hepatotoxicity. Hepatocellular damage by reactive carbon tetrachloride metabolites," Zeitschrift für Naturforschung C, vol. 56, pp. 649-659, 2001.

[30] K. Aoyama and T. Nakaki, "Glutathione in cellular redox homeostasis: association with the excitatory amino acid carrier 1 (EAAC1)," Molecules, vol. 20, no. 5, pp. 8742-8758, 2015.

[31] Y.-W. Cao, Y. Jiang, D.-Y. Zhang et al., "Protective effects of Penthorum chinense Pursh against chronic ethanol-induced liver injury in mice," Journal of Ethnopharmacology, vol. 161, pp. 92-98, 2015.

[32] K. Taguchi, H. Motohashi, and M. Yamamoto, "Molecular mechanisms of the Keap1-Nrf2 pathway in stress response and cancer evolution," Genes to Cells, vol. 16, no. 2, pp. 123-140, 2011.

[33] Y. Chen, H. G. Shertzer, S. N. Schneider, D. W. Nebert, and T. P. Dalton, "Glutamate cysteine ligase catalysis: dependence on ATP and modifier subunit for regulation of tissue glutathione levels," The Journal of Biological Chemistry, vol. 280, no. 40, pp. 33766-33774, 2005.

[34] E. Karakus, A. Karadeniz, N. Simsek et al., "Protective effect of Panax ginseng against serum biochemical changes and apoptosis in liver of rats treated with carbon tetrachloride (CCl4)," Journal of Hazardous Materials, vol. 195, pp. 208-213, 2011.

[35] B.-Y. Yang, X.-Y. Zhang, S.-W. Guan, and Z.-C. Hua, "Protective effect of procyanidin $\mathrm{B}_{2}$ against $\mathrm{CCl}_{4}$-induced acute liver injury in mice," Molecules, vol. 20, no. 7, pp. 12250-12265, 2015.
[36] K. Kim, N. Jung, K. Lee et al., "Dietary omega-3 polyunsaturated fatty acids attenuate hepatic ischemia/reperfusion injury in rats by modulating toll-like receptor recruitment into lipid rafts," Clinical Nutrition, vol. 32, no. 5, pp. 855-862, 2013.

[37] D. M. Finucane, E. Bossy-Wetzel, N. J. Waterhouse, T. G. Cotter, and D. R. Green, "Bax-induced caspase activation and apoptosis via cytochrome $\mathrm{c}$ release from mitochondria is inhibitable by Bcl-xL," The Journal of Biological Chemistry, vol. 274, no. 4, pp. 2225-2233, 1999.

[38] J.-Q. Ma, J. Ding, L. Zhang, and C.-M. Liu, "Hepatoprotective properties of sesamin against $\mathrm{CCl}_{4}$ induced oxidative stressmediated apoptosis in mice via JNK pathway," Food and Chemical Toxicology, vol. 64, pp. 41-48, 2014.

[39] D. N. Dhanasekaran and E. P. Reddy, "JNK signaling in apoptosis," Oncogene, vol. 27, no. 48, pp. 6245-6251, 2008.

[40] D.-I. Kim, S.-J. Lee, S.-B. Lee, K. Park, W.-J. Kim, and S.-K. Moon, "Requirement for Ras/Raf/ERK pathway in naringininduced G1 -cell-cycle arrest via p21WAF1 expression," Carcinogenesis, vol. 29, no. 9, pp. 1701-1709, 2008. 


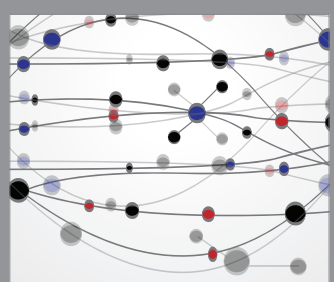

The Scientific World Journal
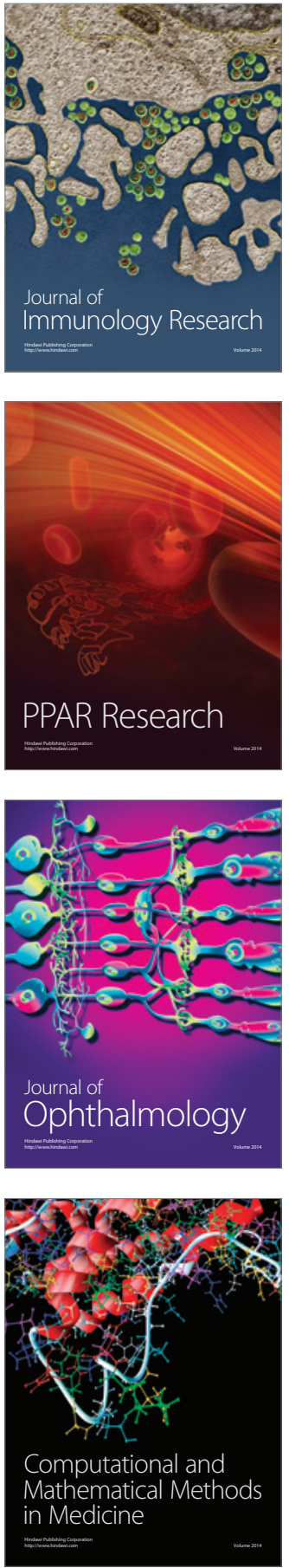

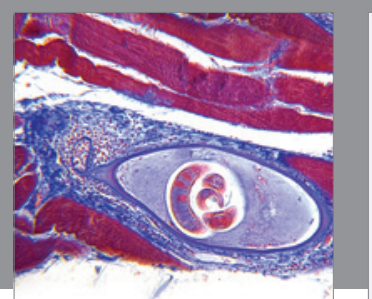

Gastroenterology Research and Practice

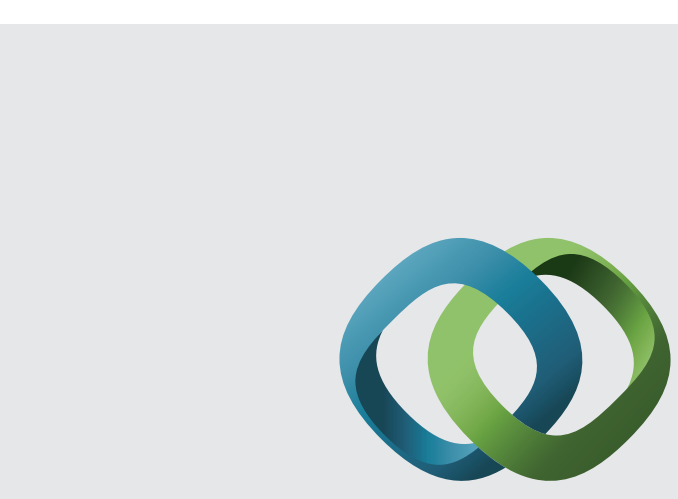

\section{Hindawi}

Submit your manuscripts at

http://www.hindawi.com
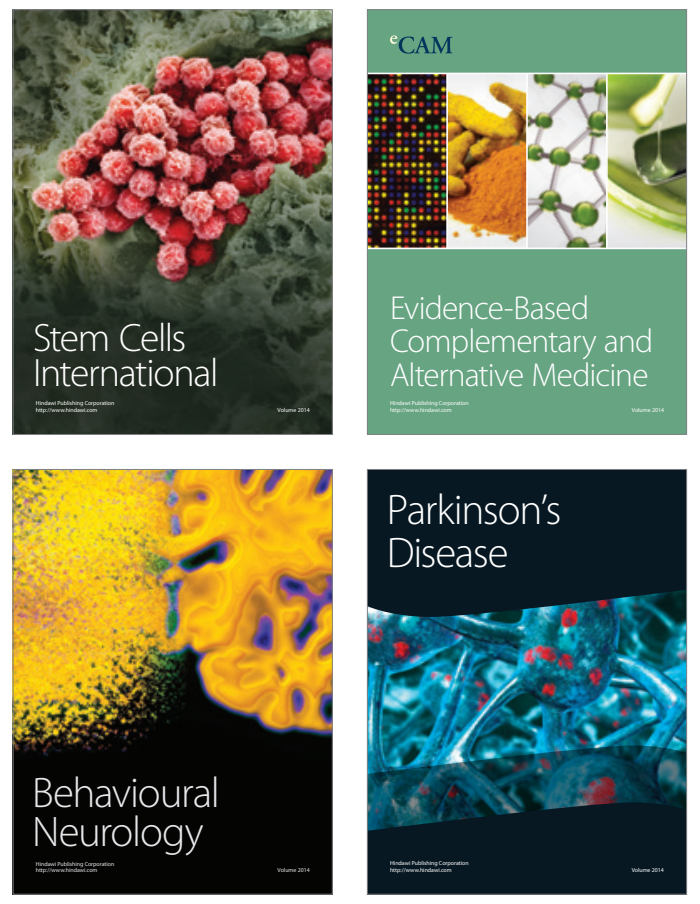
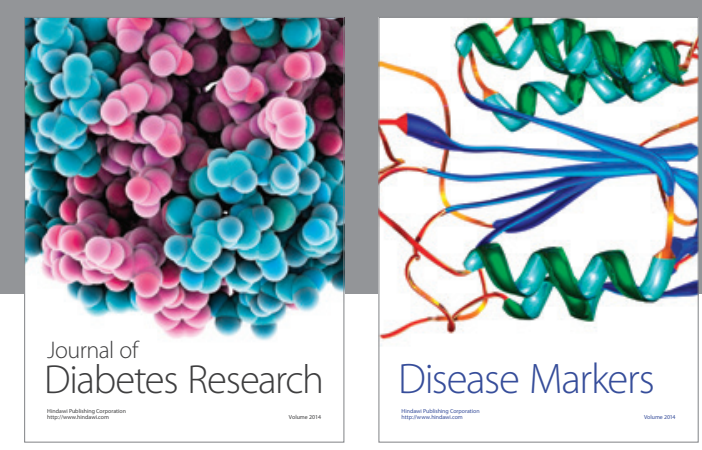

Disease Markers
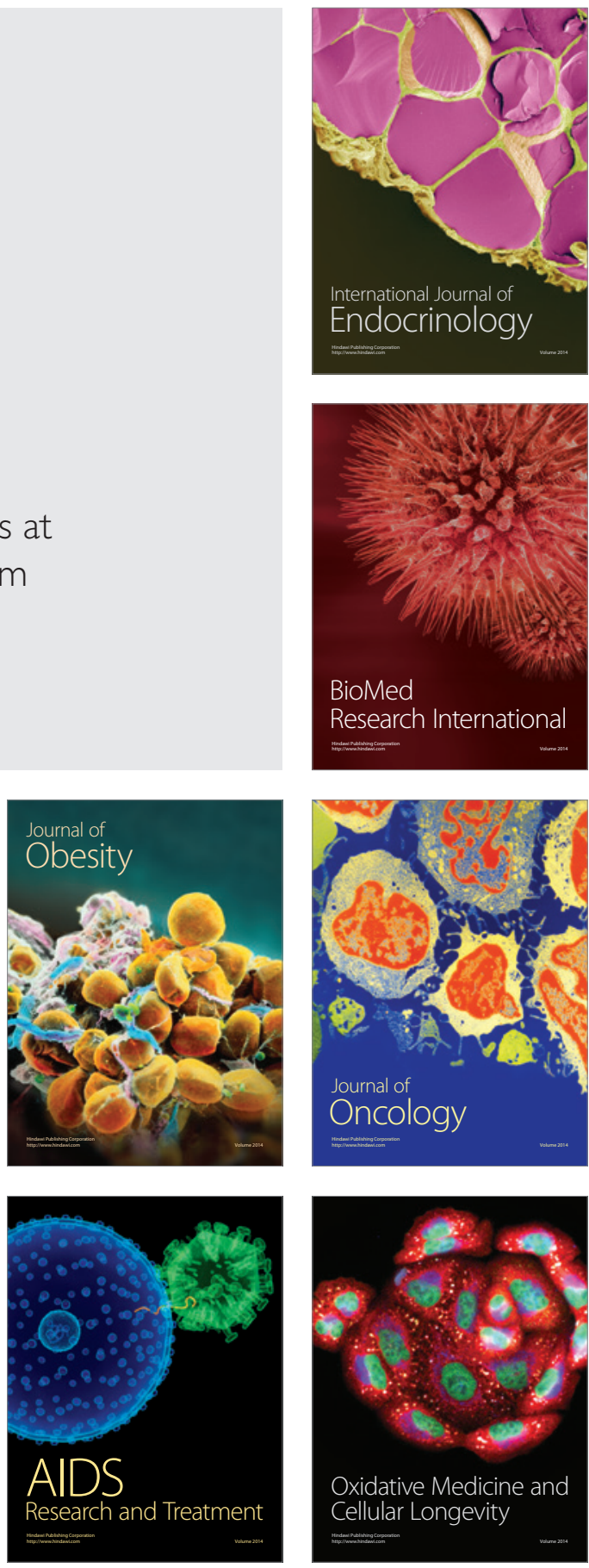